\title{
Adrenal Gland Lymphoma
}

National Cancer Institute

\section{Source}

National Cancer Institute. Adrenal Gland Lymphoma. NCI Thesaurus. Code C156945.

A rare lymphoma that arises from the adrenal gland. 